\title{
Implant Supported Overdenture: an alternative to Conventional Denture- A Case Report
}

\author{
Shayan Nazir ${ }^{1}$, Ashish Choudhary ${ }^{2}$ \\ Mohamad Imran ${ }^{3}$, Muzafar Ahmad ${ }^{4}$ \\ ${ }^{I}$ (Department of Prosthodontics, SKIMS JVC, Srinagar, India) \\ ${ }_{2}^{2}$ (Department of Prosthodontics, School of Dental Sciences, Greater Noida, India
}

\begin{abstract}
Many patients have problems adapting to their complete dentures, especially to the mandibular prosthesis. The totally edentulous patient has several options for implant treatment today, including both fixed and removable solutions. While fixed prosthesis may appear more attractive by restoring the patient closer to a truly 'dentate' status many patients are also favourable to receive a removable appliance. This removable choice has become increasingly popular during the recent global financial downturn. Many patients, especially those who are uncomfortable with dentures, have a provision for increased retention and support with implant supported overdentures. The relatively few reports on patient-based assessment of the outcome and on the functional effect of such therapy have shown better quality of life, greater patient satisfaction, better chewing and speaking performance, increased maximum myoelectric output, higher jaw-closing force, and less bone loss after implant-supported prosthetic reconstructions than with a conventional complete denture. This article presents a case report in which teeth were replaced with an implant supported overdenture.
\end{abstract}

Keywords: Mastication, Swallowing, Elderly, Implant Supported Prosthesis.

\section{Introduction}

An implant-supported overdenture (ISO) is a type of denture that is supported by and attached to implants to improve stability in the oral environment. With conventional prosthetic treatment, patient regain some mastication ability; they gain the most favourable masticatory outcomes with implant-retained prosthetic treatment [1]. Most patients report significantly more problems adapting to their mandibular denture due to a lack of comfort (increase in pain and soreness), retention, stability, and to the inability to chew and eat. Studies over the past decade have proposed the two-implant overdenture as the first treatment option after determining the benefits of a mandibular two-implant overdenture [2,3,4]. Implant supported overdenture depending on the support can be classified as: a) Implant-retained and mucous-supported overdentures, if the denture is buttressed by tissues and are retained on the implants, and b) Implant-retained and supported overdenture, if support and retention are due to the implants that behave as a fixed denture but the patient can remove it for an adequate oral hygiene.

\section{Case Report}

A patient reported to the department of Prosthodontics with a chief complain of missing teeth and wanted to get them replaced. On oral examination, the patient had few periodontally compromised posterior teeth present in the mandibular arch and some anterior teeth in the maxillary arch (Fig 1). Maxillary and mandibular diagnostic casts were made, a panoramic radiograph were taken to assess the bone for selection of implants. Radiographic examination of the patient had dense compact bone in the mandibular anterior region without any pathology. The blood reports of the patient also were checked to rule out any pathology. The patient was explained about various treatment options that is fixed implant supported prosthesis with $6 / 8$ implants and removable implant supported prosthesis with $2 / 4$ implants. Patient opted for placement of two one piece dental implants with ball attachment on the mandibular arch and overdenture over it. We decided to get the remaining teeth extracted followed by a healing time of about 6-8 months and have him a maxillary conventional denture opposing an implant supported mandibular overdenture.

\section{Treatment}

The treatment started with the extraction of the teeth with a healing period of about 8-12 months which was followed by implant placement (Stage I). Two single piece implants were placed of $13 \mathrm{~mm}$ in length and $3.75 \mathrm{~mm}$ diameter at 'B and C' positions (Fig 2). After 6 months, healing abutments were placed (Fig 3) and preliminary impressions of upper and lower arches made. Border moulding and final impressions were made with a custom tray (Fig 4) which was modified in the areas of the healing screws. Jaw relation was recorded followed by teeth arrangement. Balancing was done to make the denture stable followed by try-in prior to 
processing of the denture (Fig 5). At the stage of the denture insertion, the ball attachments were screwed onto the implant and ball housings attached at the ball end (Fig 6\&7). Space was created on the intaglio surface of the denture corresponding to the opposing implant abutments. The space was filled with auto-polymerizing acrylic resin for relining and the denture was inserted in the patients mouth and he was asked to close into maximum intercuspation. After complete polymerization, the denture was removed and the flash on the intaglio surface was trimmed and smoothened (Fig 8 \& 9). The patient was recalled after 24 hours for minor denture adjustments, retention, stability, occlusal adjustments. The patient was called for regular recall visits for the maintenance of the attachment system, to monitor implant osseointegration with marginal bone loss and the health of the oral and periimplant tissues.

\section{Discussion}

Edentulism is characterised by atrophy of the jaw bone. Studies have shown an average of $4 \mathrm{~mm}$ bone resorption occuring during the first year of tooth loss and thereby decreasing to $0.5 \mathrm{~mm}$ per year. Vertical bone height of about $5.2 \mathrm{~mm}$ is lost under complete dentures over a period of five year. Bone loss under complete dentures continues with the mandible experiencing a four times greater vertical bone loss than the maxilla. Schwartz-Arad et al found that 70 percent of their patients with implant-supported overdentures lost less than $.2 \mathrm{~mm}$ bone in the first year. Misch found that over a five- year period only .6mm of bone will be lost and longterm resorption may remain as low as $.1 \mathrm{~mm}$ per year in patients with overdentures supported by implants. Dental implants integrate with the jawbone and dramatically reduce the rate of bone loss attributed to conventional dentures. Implant-supported full bridges and dentures function like tooth roots, which preserves jaw bone. A study was conducted which showed that the patients had better denture function after implant supported overdenture (ISO) treatment. The chewing performance and maximum jaw closing force increased significantly after implant attachment. The ISO treatment increased bite force, increased chewing activity and reduced chewing cycle [5]. With conventional complete dentures, instability and pain during chewing and biting may act as limiting factors for the muscle action [6,7]. But the implant attachment stabilizes the denture and thereby permits patients to exert higher bite forces and also reduce the pain otherwise felt in the mandible during function [7]. Ball attachment are considered the simplest of attachment for clinical application with tooth or implant supported overdenture. In a comparative study with different attachment systems, the authors reported that the marginal bone stress was less in ball attachments [8]. For new denture wearers or those who have low gagging thresholds, the implant-supported overdenture may reduce the amount of soft tissue coverage and extension of the prosthesis which is of added advantage.

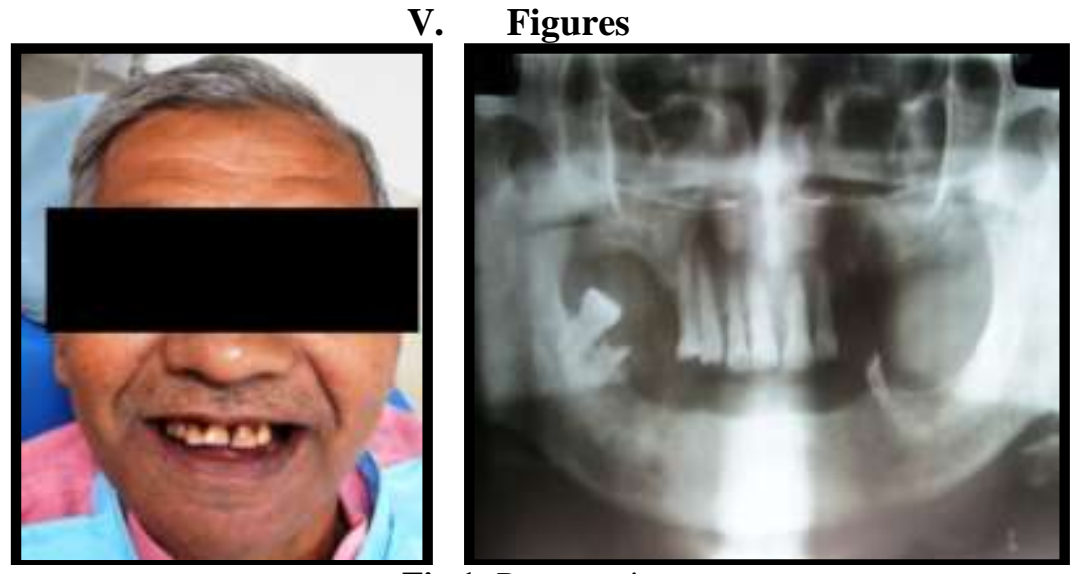

Fig 1: Preoperative

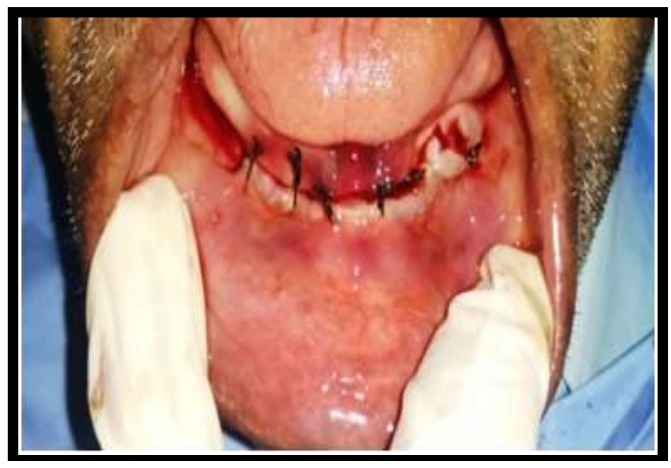


Fig 2: Implant Insertion and sutures in place

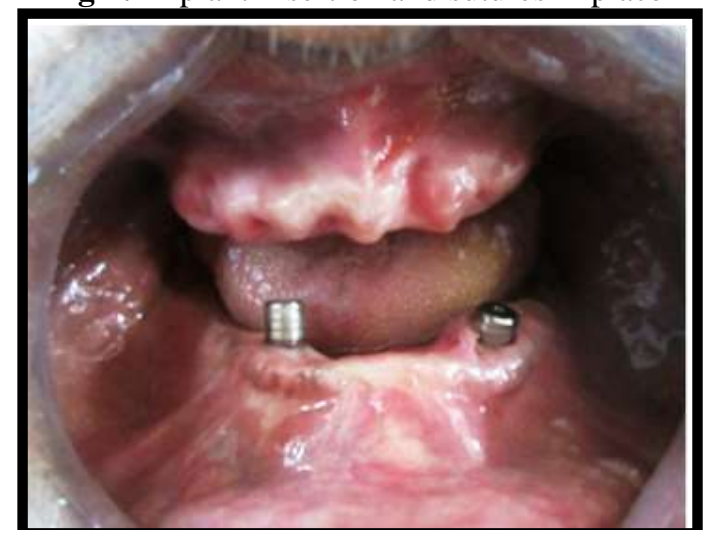

Fig 3: Healing Screw

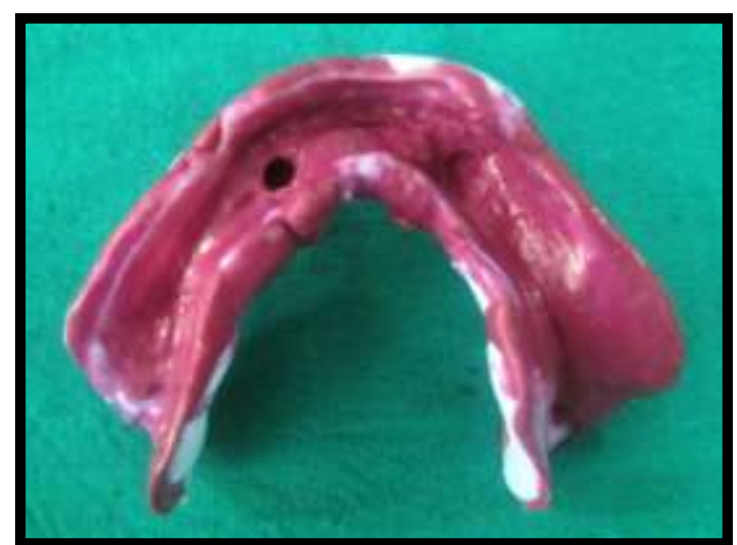

Fig 4: Final Impression of the Lower Arch

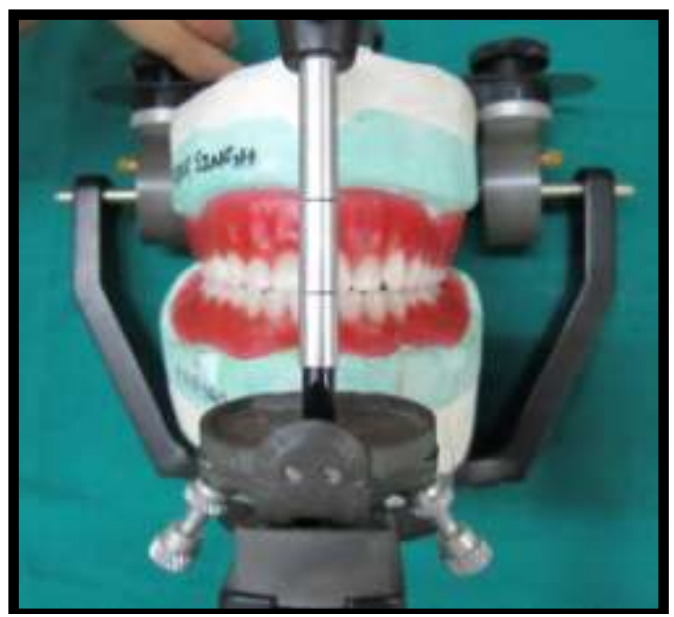

Fig 5: Balanced Denture
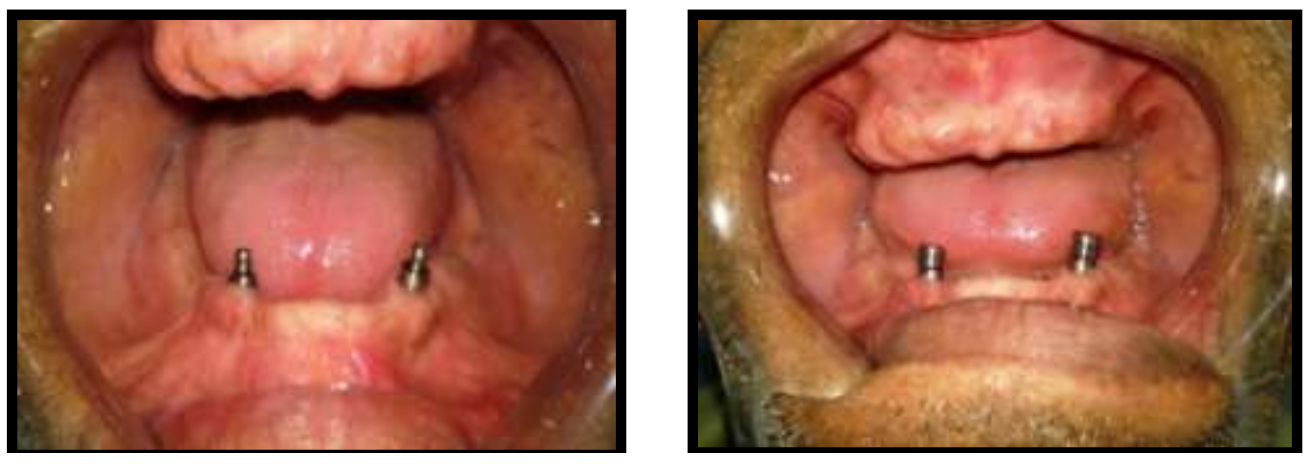
Fig 6: Ball Attachments in Place Fig 7: Metal Housings seated on Attachments for Pickup

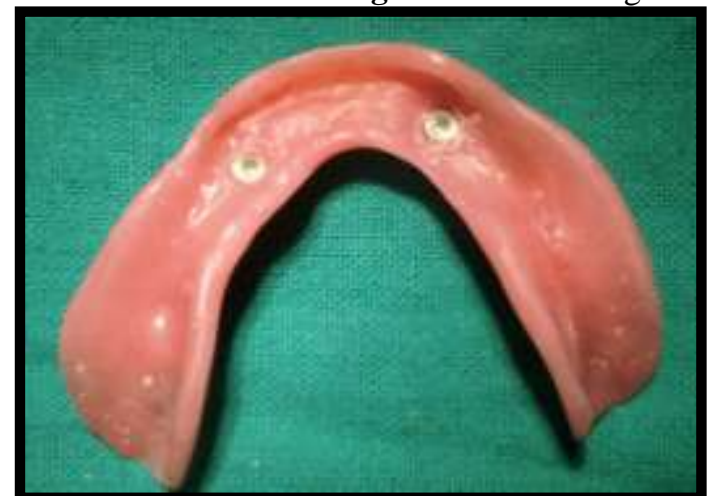

Fig 8: Metal Housings with Rings Picked up in the denture

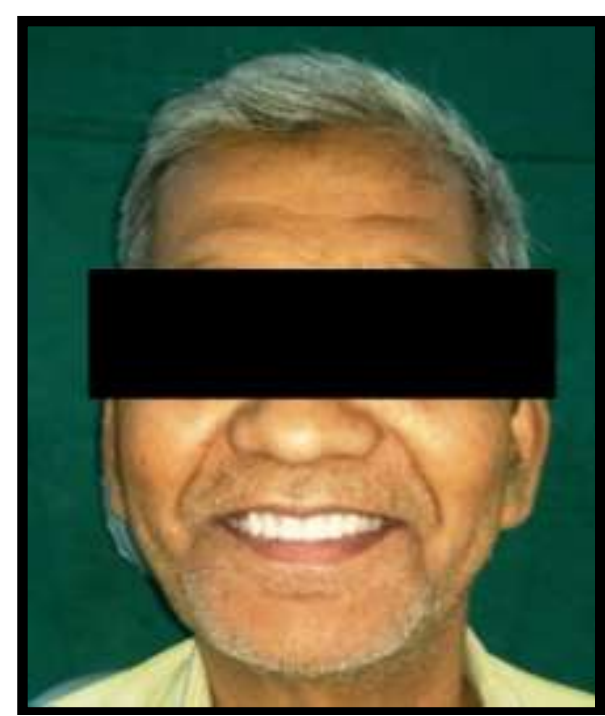

Fig 9: Postinsertion

\section{Conclusion}

Implant supported overdenture is more stable, retentive and improves the mastication and speech dramatically. Edentulous patients often do not get accustomed to wear conventional dentures. Their support is compromised by progressive bone resorption that will increase patient's instability, insecurity and discomfort. Implant supported overdentures also have a positive influence on adjacent peri-implant bone levels. It creates a sensorimotor feedback that seems to facilitate the overall functional experience with implant abutments under overdentures. Overdenture use is a cheaper treatment than fixed prosthesis. Overdenture use will prevent future aesthetic or phonetic problems in cases with lip support loss or with an interocclusal space larger than $15 \mathrm{~mm}$.

\section{References}

[1]. TangJA, Rieger JM, Wolfaardt HF. A review of functional outcomes related to prosthetic treatment after maxillary and mandibular reconstruction in patients with head and neck cancer. Int J Prosthodont. 2008; 21: 337-54.

[2]. Bakke M, Holm B, Gotfredsen K. Masticatory function and patient satisfactionwith implant-supported mandibular overdentures: a prospective 5-year study. International Journal of Prosthodontics 2002; 15:575-81.

[3]. Berretin-Felix G, Nary Filho H, Padovani CR, Trindade Junior AS, Machado WM. Electromyographic evaluation of mastication and swallowing in elderly individuals with mandibular fixed implant-supported prostheses. Journal of Applied Oral Science 2008; 16:116-21.

[4]. Carlsson GE, Lindquist LW. Ten-year longitudinal study of masticatory function in edentulous patients treated with fixed complete dentures on osseointegrated implants. International Journal of Prosthodontics 1994; 7:448-53.

[5]. Merete Bakke, Dr Odonta Betty Holm, Klaus Gotfredsen; Masticatory Function and Patient Satisfaction with Implant-Supported Mandibular Overdentures: A Prospective 5-Year Study; The International Journal of Prosthodontics; Volume 15, Number 6, 2002.

[6]. Tallgren A, Holden S, Lang BR, Ash MM. Jaw muscle activity in complete denture wearers-A longitudinal electromyographic study. J Prosthet Dent 1980; 44:123-132.

[7]. Fontijn-Tekamp FA, Slagter AP, van't Hof MA, Kalk W, Jansen JA. Pain and instability during biting with mandibular implant retained overdentures. Clin Oral Implants Res 2001; 12:46-51.

[8]. Menicucci G, Lorenzetti M, Pera P, Preti G. Mandibular implant-retained overdenture: finite element analysis of two anchorage systems. Int J Oral Maxillofac Implants. 1998; 13:369-76. 